Elsevier required licence: (C) 2018

This manuscript version is made available under the CC-BY-NC-ND 4.0 license http://creativecommons.org/licenses/by-nc-nd/4.0/

The definitive publisher version is available online at https://doi.org/10.1016/j.psep.2018.05.006 


\section{Hybrid forward osmosis-reverse osmosis for wastewater reuse and seawater 2 desalination: Understanding the optimal feed solution to minimise fouling}

3 Federico Volpin ${ }^{1, *}$, Emilie Fons ${ }^{1,{ }^{*}}$, Laura Chekli ${ }^{1}$, Jung Eun $\mathrm{Kim}^{1}$, Am Jang ${ }^{2}$ and Ho Kyong Shon ${ }^{1, * *}$ 4

$5{ }^{1}$ School of Civil and Environmental Engineering, University of Technology Sydney (UTS), City Campus, 6 Broadway, NSW 2007, Australia

$7{ }^{2}$ Graduate School of Water Resources, Sungkyunkwan University, Jangan-gu, Suwon, Gyeonggi-do, 16419, $8 \quad$ Republic of Korea

9

10

11

12

13

14

15

16

17

18

19

20

21

$22{ }^{*}$ F.V. and E.F. equally contributed to this work

23

24

${ }^{* *}$ Corresponding author: Tel.: (+61) 029514 2629; email: Hokyong.Shon-1@uts.edu.au 


\section{Abstract}

26 To enhance the seawater desalination energy efficiency forward osmosis - reverse osmosis (FO-RO)

27 hybrid system has recently been developed. In this process, the FO "pre-treatment" step is designed to

28 dilute the seawater (SW) with reclaimed wastewater (WW) before the desalination step, thereby

29 reducing the energy demand for the SWRO process. However, membrane fouling is a major issue that

30 needs to be addressed. Proper selection of suitable WWs is necessary before proceeding with large-

31 scale FO-RO desalination plants. In this study, long-term experiments were carried out, using state-of-

32 the-art FO membrane with real WW solutions. A combination of water flux modelling and membrane

33 characterisation were used to fouling to process performance. Initial water fluxes as high as $22.5{\mathrm{~L} . \mathrm{m}^{-}}^{-}$

$34{ }^{2} \cdot h^{-1}$ were observed when using biologically treated secondary effluent. It was also found that secondary

35 effluents cause negligible flux decline. On the other hand, biologically treated wastewater and raw

36 wastewater caused mild and severe flux decline respectively ( $25 \%$ and $50 \%$ of flux decline after $80 \mathrm{hrs,}$

37 compared to no-fouling conditions). Ammonia leakage to the diluted seawater was also measured,

38 concluding that, if biologically treated wastewater is used as feed, the final $\mathrm{NH}_{4}{ }^{+}$concentration in the

39 draw is likely to be negligible.

46 Keywords: Forward osmosis; membrane fouling; osmotic dilution; seawater; wastewater. 


\section{$47 \quad 1$ Introduction}

48 Ensuring availability and sustainable management of water and sanitation for all was one of the 17 49 Sustainable Development Goals put forward by the United Nations for the 2030 Agenda [1]. The lack 50 of access to clean water is a significant health concern in developing countries, as more than 2 billion 51 people live without proper sanitation, and millions die from waterborne diseases every year [2]. At the 52 beginning of the millennium, about $27 \%$ of the world population already lived in water-stressed regions, 53 and this number is expected to keep rising as these regions are now experiencing population growth and industrialisation [3]. Moreover, one of the several consequences of climate change is putting an additional strain on water resources all over the world. In 2014, the $5^{\text {th }}$ assessment report of the international panel on climate change warned against the possible adverse impacts of increased greenhouse gases emissions on renewable freshwater availability and safety, especially in presently dry regions [4]. Shannon et al. [5] highlighted several paramount research areas where further work is needed to ensure more efficient and sustainable use of water resources. Among them are the reclamation of impaired water and desalination.

With more than $97 \%$ of the world's water being seawater or brackish water, desalination technologies have been seen as a way to drastically increase the water supply thereby getting closer to meeting the future water demand. The first desalination plants have been opened in the middle of the twentieth century and relied on thermal processes to treat the saline feeds and produce fresh water. Since then, membrane processes have proven to be less energy-intensive, and seawater reverse osmosis (SWRO) is now used in most desalination plants [6]. Reverse osmosis (RO) is the most widespread waterpurifying technique. It applies hydraulic pressure to overcome the osmotic pressure of a solution, thereby allowing water from a saline or contaminated feed stream (e.g., seawater, brackish water, wastewater) to cross a semi-permeable membrane while rejecting ions and other contaminants. The produce water costs of current RO designs in SWRO plants lies between 0.5-1 USD $\mathrm{m}^{-3}$ [7]. However, the SWRO energy consumption is not expected to improve as we are near the limit set by thermodynamics [8]. Making use of impaired water sources could be a way to reduce the produced water cost [7]. However, if wastewater is sent directly through an RO process, irreversible fouling of the RO membrane is expected to occur [9].

In alignment with the principles of circular economy, reclamation means viewing wastewater (WW) as a possible valuable resource and not as pure waste that needs to be disposed of. It is, however, paramount to find non energy intensive technologies. This is to reduce, or at least not increase, the achieved, the treated effluents can even be made available for re-use, e.g. irrigation, toilet flushing, cooling towers, etc. [10]. 
81 Because of its lower irreversible fouling propensity, forward osmosis (FO) was recently investigated as 82 SWRO pre-treatment to make use of impaired water sources (e.g., wastewater primary or secondary effluent) to reduce the fresh water production cost [7]. In the FO pre-treatment step, seawater is used as a draw solution (DS) to extract water from an impaired water source. Water transport is created as the osmotic pressure of seawater (i.e., 25-30 bars) is much higher than the one of sewage wastewater (i.e., 0.3-1 bar). Afterwards, the diluted seawater is sent through the SWRO filtration to produce fresh water. This pre-treatment step lowers the SWRO operating pressure, as it reduces the osmotic pressure of seawater, thereby moderating the energy demand of the desalination step. As aforementioned, due to the absence of hydraulic pressure, the FO process was found to be less prone to irreversible fouling

90 [11]. This application that is particularly interesting is the use of reclaimed WW [12], as it will also 91 produce concentrated dewatered waste that can be reused for nutrients recovery or disposed of.

92 Several researchers have investigated the performance and feasibility of the FO-RO hybrid system, both 93 at lab-scale and pilot-scale, using different types of FO membranes [13-16]. However, at this stage, this 94 process is still not ready for large-scale implementation, primarily because of the issue of membrane fouling. Fouling, which is the deposition of different components (organic, inorganic, or living matter) on the membrane, is a recurrent problem when working with challenging stream such as wastewater

97 [17]. Despite the lower fouling propensity of FO compared to SWRO, when high fouling potential solutions are used, i.e. raw WW, this issue persists. Strategies need to be systematically developed to lessen the impact of this phenomenon as it decreases the water flux and affects the product water quality 100 while damaging the membrane, hence increasing the operational and capital costs. Although raw WW 101 is cheap and readily available, removals of membrane fouling promoters are still necessary before the 102 FO filtration. As pre-treatment operations will inevitably increase the overall cost, a trade-off needs to 103 be found between membrane fouling and an acceptable number of pre-treatment steps. Understanding 104 the degree of raw WW pre-treatment is necessary to minimise the process cost and therefore to select 105 the best feed for this application is crucial to ensure optimal process operation.

106 With these premises, the primary objectives of this study were the following: (i) To assess the fouling 107 behaviour on newly developed thin film composite (TFC) FO membranes using real wastewater and 108 seawater solutions. (ii) To evaluate the influence of pre-treatment of wastewater solutions on the fouling 109 potential and the quality of the product seawater. (iii) To understand the nitrogen leakage to the seawater 110 draw solution. 


\section{Materials and Methods}

\section{$113 \quad 2.1 \quad$ FO membrane}

114 Thin film composite (TFC) flat-sheet membranes (Toray Industries, Korea) were employed in this 115 study. The thin active layer is made of polyamide and is attached to a polysulfone support layer in which 116 a woven mesh was embedded for better mechanical strength. SEM images of the membrane are shown

117 in Figure 1. The TFC FO membranes used in this study were about $75 \mu \mathrm{m}$ thick with a highly porous 118 support layer and a thin active layer with tight pores.
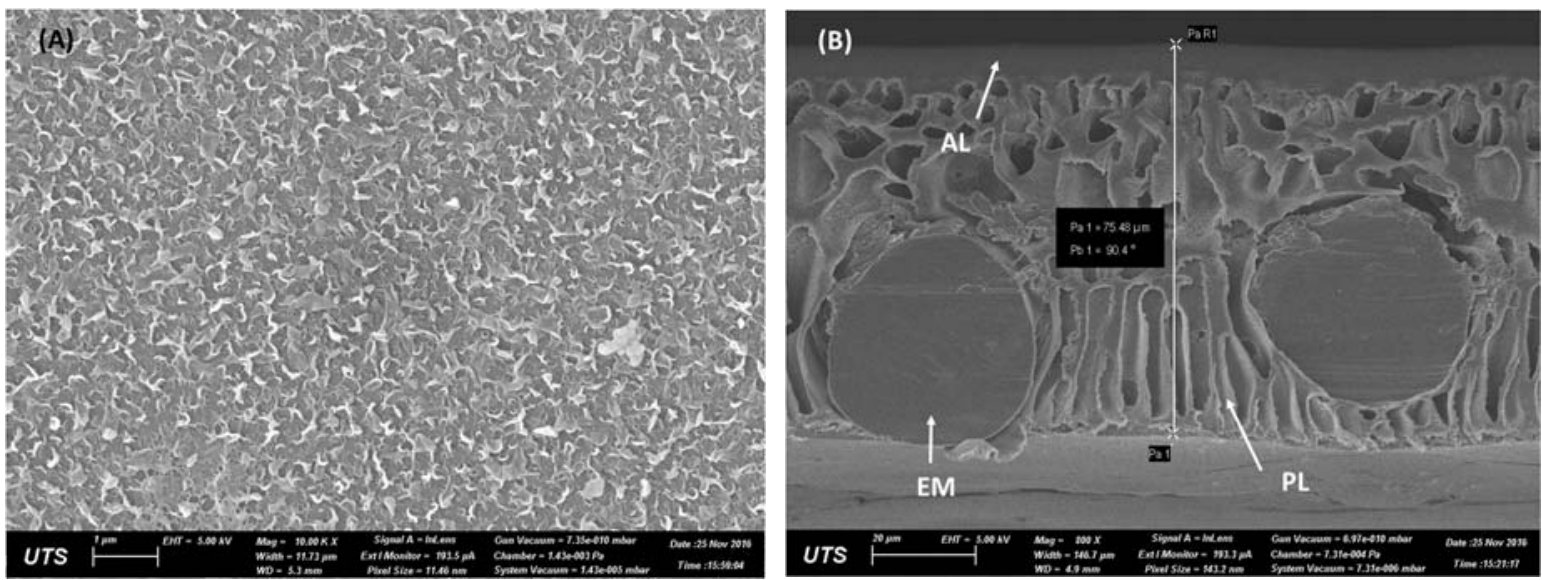

Figure 1: a) Active layer surface $(x$ 30,000). b) side-view of the membrane (800x). The thin active layer (AL) is resting on top of the porous support layer (PL) (EM: embedded mesh)

\subsection{Bench-scale FO system}

123 An acrylic FO cell with an active membrane area of $20.02 \mathrm{~cm}^{2}$ was connected to two variable-speed 124 gear pumps (Cole Palmer, VT, USA), and the solutions were stored in two 5 L plastic tanks. Figure S1 125 displayed the schematic representation of the system. The pump flow velocity was set to $400 \mathrm{~mL} / \mathrm{min}$ $126(8.5 \mathrm{~cm} / \mathrm{s})$ for all experiments, and the solutions were pumped through the membrane cell in counter127 current mode. FO experiments were conducted in batch mode, with constant recycling of the feed and 128 draw solutions to their respective tank. The active layer of the FO membrane faced the FS (FO mode).

129 The weight of the draw tank was continuously monitored using a digital $15 \mathrm{~kg}$ scale (Adam Equipment 130 PGL-15001 Precision Balance $15 \mathrm{~kg} \times 0.1 \mathrm{~g}$ ) and was used to calculate the variation of water flux 131 throughout the experiments. A temperature control system connected to a water bath was used to keep 132 both solutions at $25^{\circ} \mathrm{C}$. Conductivity, total dissolved solids (TDS) and $\mathrm{pH}$ were monitored using an 133 HQ30D portable multi-meter (Hach, CO, USA). The reverse salt flux $J_{S}\left(R S F, g / \mathrm{m}^{2} / \mathrm{h}\right.$ ) was calculated 134 based on the conductivity measured continuously in the feed solution as: 
136 Where $\lambda(\mathrm{cm} / \mathrm{S} / \mathrm{L})$ is a conductivity calibration factor. This was obtained by linear regression of the 137 conductivity of $\mathrm{NaCl}$ solutions as a function of its concentration (i.e. conductivity $=(1 / \lambda) *$ mass 138 concentration of $\mathrm{NaCl}$ ), $\mathrm{C}_{\mathrm{F}}$ is the conductivity of the feed solution, $\mathrm{V}_{\mathrm{F}}$ is the volume of the feed solution.

139 The specific reverse salt flux (SRSF, g/L) was calculated as follows:

$140 \quad \mathrm{SRSF}=\frac{J_{S}}{\mathrm{~J}_{W}}$

\section{$141 \quad 2.3 \quad$ Feed and draw solutions}

142 Real seawater was collected from the faculty of science at the University of Technology, Sydney (UTS).

143 Johns Water Exchange provided the seawater to the university after its collection in Rose Bay, Sydney.

144 The seawater was pre-treated directly at UTS with a five $\mu \mathrm{m}$ filtration bag and a UV filter sterilizer.

145 These pre-treatment steps were necessary to reduce the risk of fouling and biofouling within the support

146 layer. Real wastewater was collected from the wastewater treatment plant in Central Park, Sydney. In

147 this plant, the wastewater undergoes different treatment steps as shown in Figure S2. In this Figure, the

148 FS sampling locations were also outlined. In fact, solutions were collected at various points to assess

149 the impact of pre-treatment of the feed solutions:

1. Primary effluent (i.e. solution 4, Primary Eff.). The raw municipal WW was pre-treated in two different ways to remove large particles that could instantly damage the membrane. The first is a simple settling (for two days) and the second is coagulation-flocculation $\left(10 \mathrm{~g} / \mathrm{L}\right.$ of $\mathrm{FeCl}_{3}$ was used as a coagulant).

2. Mixed liquor before ultrafiltration (i.e. solution 3, also referred to as Mixed Liq). This consists of the recirculated mixed liquor together with the activated sludge. For the same reason of the primary effluent, the mixed liquor was either filtered using $1.2 \mu \mathrm{m}$ paper filters or left to settle down during two days. After settling down, the supernatant was collected using a peristaltic pump.

3. Secondary effluent i.e., mixed liquor after ultrafiltration (i.e. solution 2, Secondary Eff.). This

162 Synthetic seawater was prepared by dissolving $0.6 \mathrm{M}$ of sodium chloride (i.e. $\mathrm{NaCl}, 35 \mathrm{~g} / \mathrm{L}$ ) in deionized

163 (DI) water. This is the approximate concentration in real seawater in Sydney. For the real seawater, its

164 composition is displayed in table 2.

165 All solutions were stored in the fridge and the dark before use. Wastewater and seawater solutions were 166 used within a week after sampling. 
168 2.4.1 Determination of membrane parameters

169 Three key membrane parameters were determined to model the FO water flux: the pure water 170 permeability coefficient $\mathrm{A}\left(\mathrm{Lm}^{-2} \mathrm{~h}^{-1} \mathrm{bar}^{-1}\right)$, the salt permeability coefficient $\mathrm{B}\left(\mathrm{Lm}^{-2} \mathrm{~h}^{-1}\right)$ and the 171 membrane structural parameter $\mathrm{S}(\mu \mathrm{m})$. The A and B parameters represent the transport of water and 172 salts through the membrane, while $\mathrm{S}$ indicates the solute transport in the support layer. The membrane 173 parameters were determined using the methodology described by Tiraferri et al. [18]. Four consecutive 174 FO experiments were run for 1 hour with DI water as feed solution. Initial volumes were set to $2 \mathrm{~L}$. The 175 DSs were prepared with different concentrations of $\mathrm{NaCl}(0.5 \mathrm{M}, 1 \mathrm{M}, 1.5 \mathrm{M}$ and $2 \mathrm{M})$.

\subsubsection{Short-term experiments using synthetic seawater and real wastewater}

177 Seven baseline experiments were conducted with different real wastewater feed solutions (Table 1). 0.6 $178 \mathrm{M} \mathrm{NaCl}$ solution was used as a DS for 6 of the tests, and real seawater was used in only one experiment 179 to check that the behaviour of seawater was similar to the one of the synthetic solution. Real seawater 180 was not used for the baseline experiments because one of the goals was to carry out mineral and organic 181 analyses on the final draw solution, to see the nutrients leakage, and real seawater would have made it 182 difficult given its inevitable variability of the initial composition of real seawater. All experiments were 183 conducted for 8 hours with $2 \mathrm{~L}$ of FS and DS. The relative flux decline was plotted to assess the impact 184 of the wastewater composition. used, while $4 \mathrm{~L}$ of FS was used for the long-term one.

\begin{tabular}{|c|c|c|}
\hline Experimental Period & Feed Solution (FS) & Draw Solution (DS) \\
\hline \multirow{7}{*}{ Short-term experiment (8 hr) } & DI water & $0.6 \mathrm{M} \mathrm{NaCl}$ \\
\hline & DI water & Real Seawater \\
\hline & Secondary effluent (Secondary Eff.) & $0.6 \mathrm{M} \mathrm{NaCl}$ \\
\hline & $\begin{array}{l}\text { Mixed liquor after filtration } 1.2 \text { microns (Mixed } \\
\text { Liq,f) }\end{array}$ & $0.6 \mathrm{M} \mathrm{NaCl}$ \\
\hline & Mixed liquor after settling (Mixed Liq,s) & $0.6 \mathrm{M} \mathrm{NaCl}$ \\
\hline & $\begin{array}{l}\text { Raw WW after coagulation-flocculation } \\
\text { (Primary Eff,cf) }\end{array}$ & $0.6 \mathrm{M} \mathrm{NaCl}$ \\
\hline & Raw Wastewater after settling (Primary Eff,s) & $0.6 \mathrm{M} \mathrm{NaCl}$ \\
\hline \multirow{3}{*}{ Long-term experiment $(80 \mathrm{hr})$} & Secondary effluent (Secondary Eff.) & Real Seawater \\
\hline & Mixed liquor after settling (Mixed Liq) & Real Seawater \\
\hline & $\begin{array}{l}\text { Raw WW after coagulation-flocculation } \\
\text { (Primary Eff.) }\end{array}$ & Real Seawater \\
\hline
\end{tabular}


190 Three long-term experiments were conducted, with the duration of 80 hours, to investigate the long191 term flux decline and fouling behaviour of wastewater in actual conditions. The initial volume of the 192 FS was set to $4 \mathrm{~L}$. An initial amount of $2 \mathrm{~L}$ of real seawater was used as a draw solution for all the 193 experiments. Table 1 displayed the different FS and DS used for the experiments. At the end of each 194 experiment, the membrane was collected for further analyses of the fouling layer and determination of 195 the primary fouling precursors in real solutions.

\section{$196 \quad 2.5 \quad$ Modelling the water flux of the FO experiments}

197 To better understand the impact of fouling using different types of wastewater streams and how the 198 water flux $\left(\mathrm{J}_{\mathrm{w}}\right)$ deviates from the theoretical one. Water flux was modelled via the classical solution199 diffusion model coupled with the diffusion-convection transport in the membrane support layer [19]. 200 Membrane pure water permeability (A), $\mathrm{NaCl}$ salt permeability coefficients (i.e., $\mathrm{B}_{\mathrm{NaCl}}$ ) and structural 201 parameters $\mathrm{S}$ were obtained as above described. The results are shown in Table 4. The effect of the internal concentration polarization (ICP), on the porous support layer of the FO membrane, was taken into account in the equation used. Since all the experiments have been carried out in FO mode (i.e., active layer (AL) facing the feed solution (FS)), equation (3) was used to predict the water flux $[19,20]$.

$J_{w}=\sigma K_{m} \ln \left(\frac{A \pi_{D}+B_{S}}{A \pi_{F}+J_{w}+B_{S}}\right) \quad(\mathrm{AL}-$ facing FS $)$

In this equation, $\sigma$ is the reflection coefficient, assumed as unity (complete rejection of the solute), $K_{m}$ is the mass transfer coefficient of $\mathrm{NaCl}$, given as salt diffusivity divided by $\mathrm{S}$. The bulk osmotic pressures of the draw and feed are displayed as $\pi_{D}$ and $\pi_{F}$ are the DS and FS bulk osmotic pressure respectively.

\subsection{Analytical methods}

211 Several analyses were carried out on the solutions before, during and after the FO filtration. Cation and

212 anion concentrations were respectively measured using a 4100 MP-AES (Agilent Technologies, VI,

213 Australia) and a 790 Personal IC (Metrohm, Switzerland). Spectroquant ${ }^{\circledR}$ Cell Test kits and Reagent

214 Test kits (Merck Millipore, Germany) were also used to measure the concentrations of anions and

215 cations $\left(\mathrm{Cl}^{-}, \mathrm{PO}_{4}{ }^{3-}, \mathrm{NO}_{3}{ }^{-}\right.$and $\left.\mathrm{NH}_{4}{ }^{+}\right)$, and for the determination of total phosphorus, total nitrogen, and

216 COD values. A 2100P Portable Turbidimeter (Hach, CO, USA) was used to determine the turbidity

217 values of wastewater samples. Dissolved organic carbon (DOC) values were measured using a multi

218 N/C® 3100 TOC Analyzer (Analytik Jena, Germany). Prior to the TOC analysis, samples were filtered 219 using a $0.45 \mu \mathrm{m}$ filter to obtain the DOC values. Total suspended solids (TSS) values were calculated 220 upon filtration of the solution with a $0.45 \mu \mathrm{m}$ ceramic filter, drying off the clogged filter in a $104^{\circ} \mathrm{C}$ 
oven and measurement of the weight increase of the filter. The osmotic pressure of the solutions was computed using OLI Stream Analyser 3.2 (OLI System Inc., Morris Plains, NJ, US). The detailed organic matter characterisation of the real wastewater was performed using liquid chromatographyorganic carbon detection or LC-OCD (DOC-Labor, Germany) as per the procedure described elsewhere $[21]$.

\subsection{Membrane analysis}

Following the long-term experiments, the three fouled membranes were collected and dried off in an oven at $50^{\circ} \mathrm{C}$. The surface of the active layer was measured by scanning electron microscopy (SEM) using a SUPRA 55-VP instrument (Zeiss, Germany). Before the SEM analyses, the membrane samples were coated with a palladium-gold layer using an EM ACE 600 coater (Leica, Germany). The elements composing the fouling layer on the membrane were determined by electron - dispersive X - Ray (EDX). The cake layer was also analysed by Fourier transform infrared (FTIR) Spectroscopy using the IRAffinity-1 from Shimadzu (Japan).

\section{Results and Discussion}

\subsection{Feed and draw solution characterisation}

237 After conducting all the chemical analysis on the different types of real WW used as FS, a full 238 characterization was obtained. Table 2 shows the initial composition of the real WW ans SW samples utilised for the experiments. It can be seen th, while Table 3 displays its LC-OCD fractionation.

240 Additionally, in Table S1 the turbidity values before and after the pre-treatments are shown. From the

241 LC-OCD fractionation data, it can be seen that there is a much higher concentration of low molecular 242 weight neutrals organic compounds (LMW neutrals) in the primary effluent compared to the mixed 243 liquor. This is expected as, when the primary effluent is mixed with the biomass in the aerobic reactor, 244 the carbon source in the WW is first absorbed and then gradually degraded by the heterotrophic bacteria community.

In terms of filtration, these compounds are likely to have higher fouling propensity compared to larger molecular weight one. In fact, they could stick on the rough membrane promoting the attachment of other organic or inorganic compounds. 
Table 2 Composition of the real seawater and wastewater solutions used in all the experiments. Feed and draw samples were collected at the beginning and the end of each experiments. * The osmotic pressure was calculated via OLI Stream Analyser 3.2 (OLI System Inc., Morris Plains, NJ, US).

\begin{tabular}{|c|c|c|c|c|c|}
\hline & & \multirow{2}{*}{$\begin{array}{l}\text { SEAWATER } \\
\text { (Rose Bay. } \\
\text { Sydney) }\end{array}$} & \multirow{2}{*}{$\begin{array}{l}\text { Mixed liquor } \\
\text { (Central Park. } \\
\text { Sydney) }\end{array}$} & \multirow{2}{*}{$\begin{array}{c}\text { Secondary } \\
\text { effluent } \\
\text { (Central Park. } \\
\text { Sydney) }\end{array}$} & \multirow{2}{*}{$\begin{array}{c}\text { Primary } \\
\text { effluent } \\
\text { (Central } \\
\text { Park. } \\
\text { Sydney) }\end{array}$} \\
\hline & & & & & \\
\hline $\mathrm{pH}$ & {$[-]$} & 7.9 & 7.38 & 7.5 & 7.9 \\
\hline COD & $\begin{array}{c}{[\mathrm{mg} / \mathrm{L}} \\
\mathrm{O} 2]\end{array}$ & {$[-]$} & 27 & 23 & 212 \\
\hline TDS & {$[\mathrm{mg} / \mathrm{L}]$} & 33100 & 357 & 336 & 646 \\
\hline Turbidity & [NTU] & 0.31 & 1.3 & 0.39 & 63.6 \\
\hline $\begin{array}{l}\text { Osmotic } \\
\text { Pressure* }\end{array}$ & [bar] & 27.16 & 0.38 & 0.335 & 0.57 \\
\hline $\mathrm{Na}^{+}$ & {$[\mathrm{mg} / \mathrm{L}]$} & 10800 & 122.5 & 113 & 142.4 \\
\hline $\mathrm{Ca}^{2+}$ & {$[\mathrm{mg} / \mathrm{L}]$} & 790 & 33.5 & 20.63 & 16.5 \\
\hline $\mathrm{Mg}^{2+}$ & {$[\mathrm{mg} / \mathrm{L}]$} & 1460 & 8 & 5.56 & 9.25 \\
\hline $\mathrm{SO}_{4}{ }^{2-}$ & {$[\mathrm{mg} / \mathrm{L}]$} & 2600 & 38 & 45.06 & 38 \\
\hline TP & {$[\mathrm{mg} / \mathrm{L}]$} & 0.51 & 7 & 3 & 22.4 \\
\hline $\mathrm{NO}_{3}^{-}$ & {$[\mathrm{mg} / \mathrm{L}]$} & 6.6 & 12.8 & 23.3 & 0.89 \\
\hline $\mathrm{NH}_{4}{ }^{+}$ & {$[\mathrm{mg} / \mathrm{L}]$} & 7.97 & 8.62 & 2.44 & 84.3 \\
\hline
\end{tabular}

Table 3. LC-OCD fractionation results of different wastewaters used in the experiments where: $L M W=$ low-molecular weight; n.q. = not quantifiable $(<1 \mu \mathrm{g} / \mathrm{L}$; signal-to-noise ratio); "Biopolymers" = polysaccharides, proteins, aminosugars; "Building blocks" = breakdown products of humics; "Neutrals" = include mono-oligosaccharides,
alcohols, aldehydes, ketones; "Acids" = summary value for monoprotic organic acids < 350 Da.



\subsection{Membrane parameters}

263 The water flux and reverse salt flux values for different concentrations of $\mathrm{NaCl}$ as $\mathrm{DS}$ are shown in

264 Figure 2. The reverse salt flux increases proportionally with the draw solution concentration. However,

265 as a consequence of the concentration polarization effect, the water flux increase was not linear with

266 the increase in osmotic pressure difference as shown by the trend of specific water flux (specific water

267 flux $\left.=\mathrm{J}_{\mathrm{w}} / \Delta \pi\right)$. 

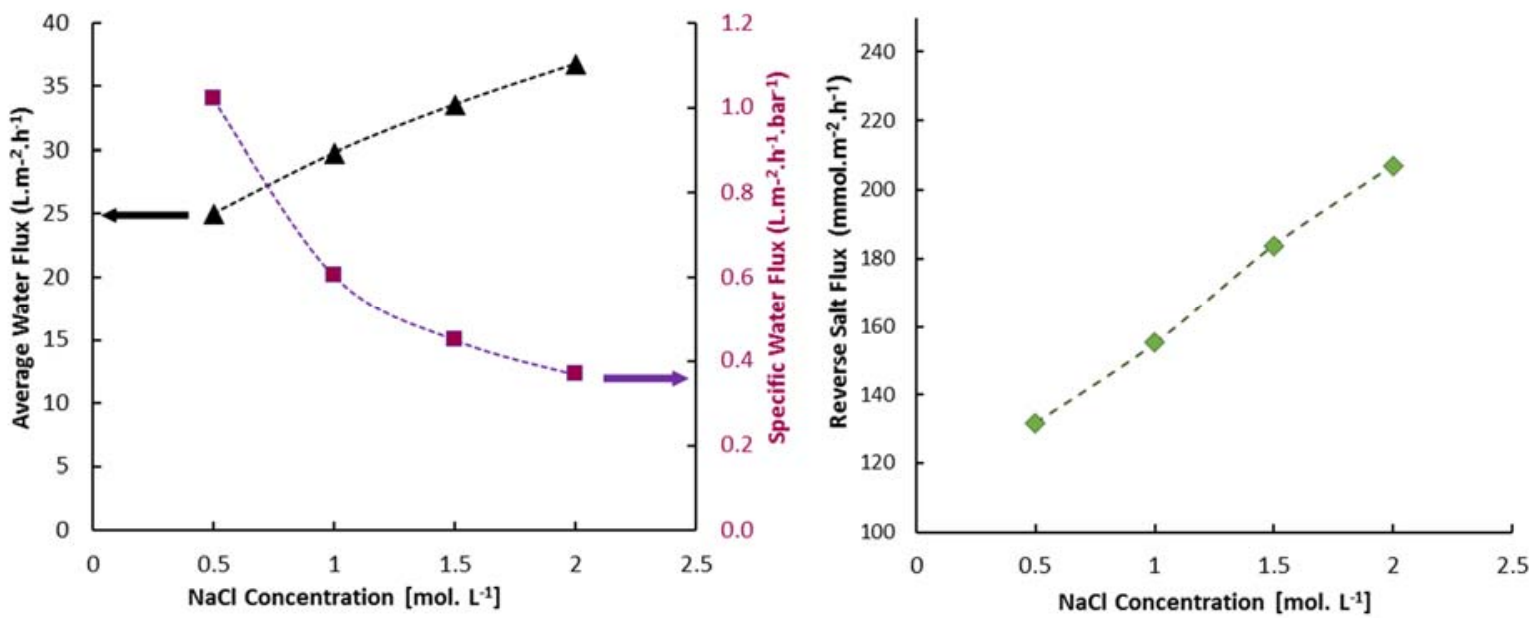

Figure 2. Baseline experiments to determine the membrane parameters (A, B, S) according to Tiraferri et al. [18]. Water flux and Reverse salt flux have been monitored for four different concentrations of $\mathrm{NaCl}$ draw solution (i.e. 0.5 , $1,1.5$ and $2 \mathrm{M}$ ) with DI water as FS. The experiments were run for 2 hours.

273 Membrane parameters were determined by using these data as input in the Tiraferri et al. algorithm 274 making sure to have an $\mathrm{R}^{2}>0.9$. The results and are presented in Table 4. As expected, the A value is 275 high compared to values found in the literature for CTA membranes (typically between 1 and 2 $276 \mathrm{LMH} /$ bar [18]). Higher water permeability of TFC compared with CTA can be explained by the 277 enhanced hydrophilicity of the TFC active layer and the fact that the porous layer is thinner, more 278 porous and less tortuous. Higher porosity and less tortuosity decrease the $\mathrm{S}$ parameter, which in turns 279 reduces the internal concentration polarisation effect. Compared to other commercial TFC membranes 280 [22, 23], Toray membranes have also slightly higher water and salt permeability coefficients. Finally, 281 the B/A ratio of the Toray membranes (Table S2) is relatively low compared to other commercial CTA 282 and TFC membranes, which indicates a good selectivity [23, 24].

Table 4. Membrane parameters of the Toray TFC membrane, determined with the methodology developed by

\begin{tabular}{ccc}
\hline Parameter & Value & Unit \\
\hline $\mathrm{A}$ & 6.47 & $\mathrm{LMH} / \mathrm{bar}$ \\
$\mathrm{B}$ & 1.74 & $\mathrm{LMH}$ \\
$\mathrm{S}$ & 409 & $\mathrm{Mm}$ \\
$\mathrm{K}$ & 0.276 & $\mathrm{~s} / \mu \mathrm{m}$ \\
\hline
\end{tabular}




\subsection{Impact of wastewater quality on the process performance and the type of fouling}

\subsubsection{Short-term experiments}

289 The water flux decline trends when using different qualities of wastewater were shown in Figure 3. The 290 initial water flux varies because of the increasing TDS amount of wastewater and the subsequent rise 291 of osmotic pressure. Because of the configuration of the experimental set-up, the DS is diluted, and the FS concentrated during the experiments. The DS dilution causes the flux to decline due to the reduction of the process driving force.

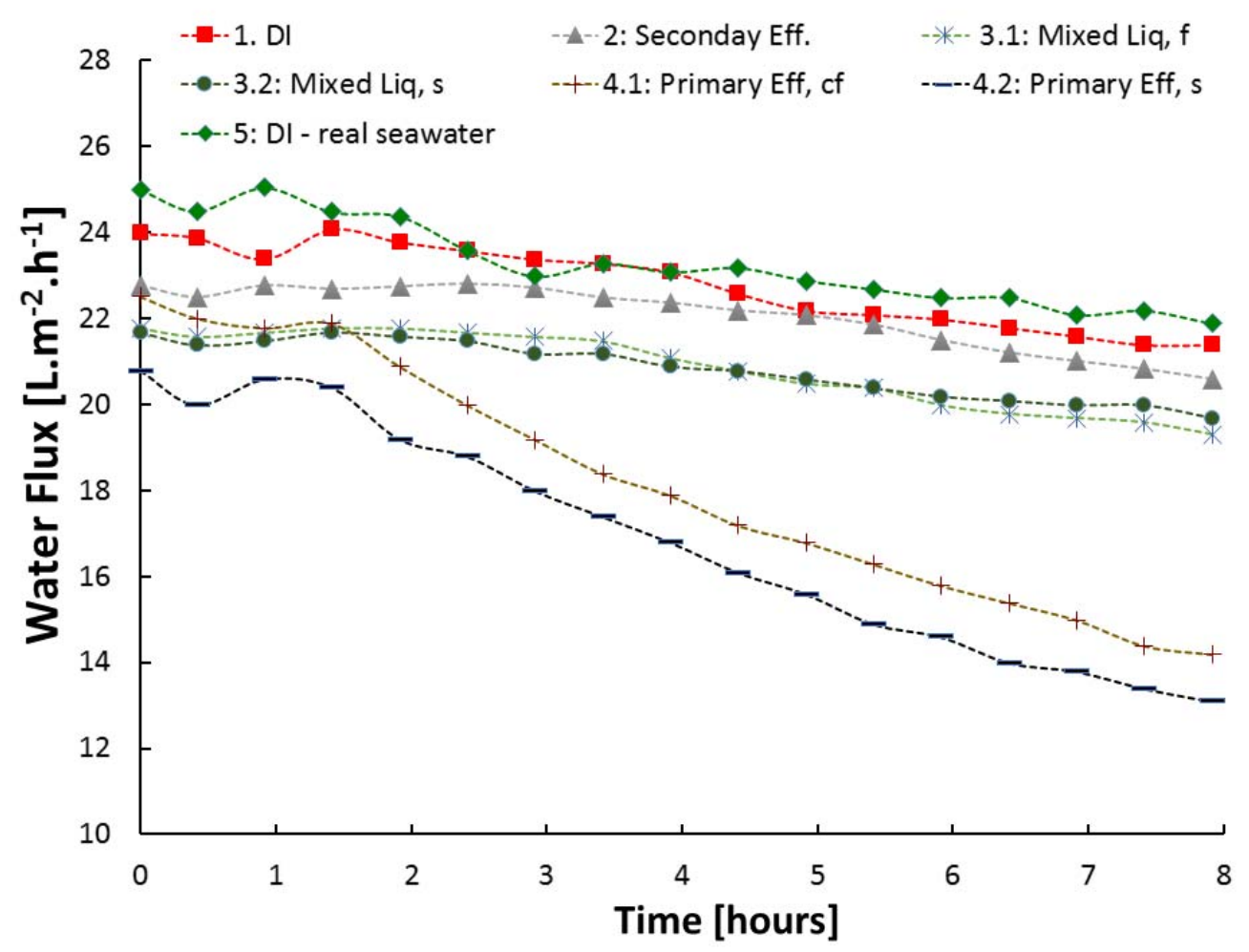

Figure 3. Water Flux for seven different feed-draw solutions couples. Operating parameters: Draw solutions $=\mathrm{NaCl}$ (except 1. Real Seawater); Feed solutions = Real Wastewater (Secondary effluent, mixed liquor pre-treated or not, primary effluent pre-treated or not); Operating time $=8$ hours.

Based on the experimental results it can be seen that, when secondary effluent or mixed liquor are used, no severe flux decline was observed. In fact, the water flux trends are similar for DI, Secondary Eff. and Mixed Liq. Low membrane fouling using biologically treated WW was also found by Cath. et al. with CTA membranes and secondary effluents [14]. However, when primary effluents (i.e. Primary Eff.) is used, severe flux decline was observed. It can be noticed that the type of pre-treatment carried out on activated sludge (3.1 and 3.2), and raw wastewater (4.1 and 4.2) did not impact the short-term water flux decline. Therefore, it can be argued that an initial biological treatment of the WW is deemed necessary if FO wants to be used as a dewatering method for WW. To conclude, different wastewaters 
307 were tested on FO using model seawater as DS. The results showed a high initial $\mathrm{J}_{\mathrm{w}}$ (22-23 LMH) using

308 the newly developed Toray TFC membrane. However, if non-biologically treated WW is used, settling

309 or coagulation-flocculation were found not sufficient to avoid quick fouling of the membrane.

\section{$310 \quad 3.3 .2 \quad$ Long-term experiments}

311 The water fluxes exhibited by the different FS during long-term experiments with real seawater (as DS)

312 and real wastewater (as FS) are displayed in Figure 4. The initial water fluxes were 23.1, 22.1, 20.5 and

313 18.8 LMH for DI water, Secondary Eff., Mixed Liq. And Primary Eff. respectively. Again, the use of

314 secondary effluent did not induce any noticeable flux decline compared to the use of DI water. However,

315 for the mixed liquor, the flux started to be impacted by fouling after 30 hours of operation and gradually

316 decreased after that. When primary effluent was used, the water flux quickly declined at the beginning

317 of the experiments, thank stabilizing to a low value after 50 hours of operation. Photographs of the

318 membranes (Figures S4 and S5) show that a uniform cake layer is rapidly built on the membrane with

319 primary effluent WW. With Secondary Eff. and Mixed Liq., a clear brown stain was visible at the outlet

320 end of the feed channel. The rest of the membrane surface was clear for Secondary Eff., but a light

321 greyish layer was visible with activated sludge. The formation of a dense cake layer explains the pattern

322 observed with primary effluent. The rapid initial flux decline is correlated to the building up of the cake

323 layer on the membrane surface. Afterwards, the plateau corresponded to a stabilization of the layer's

324 thickness which is linked to the amount of foulants in the solution and the shear force from the cross

325 flow of water.

326 A particular oscillating pattern observed for secondary effluent was also observed, and it can be

327 attributed to "self-cleaning" phenomenon. The fouling cake is detached from the membrane as soon as

328 the shear stress, caused by its thickness, is greater than its attachment to the membrane [25]. 

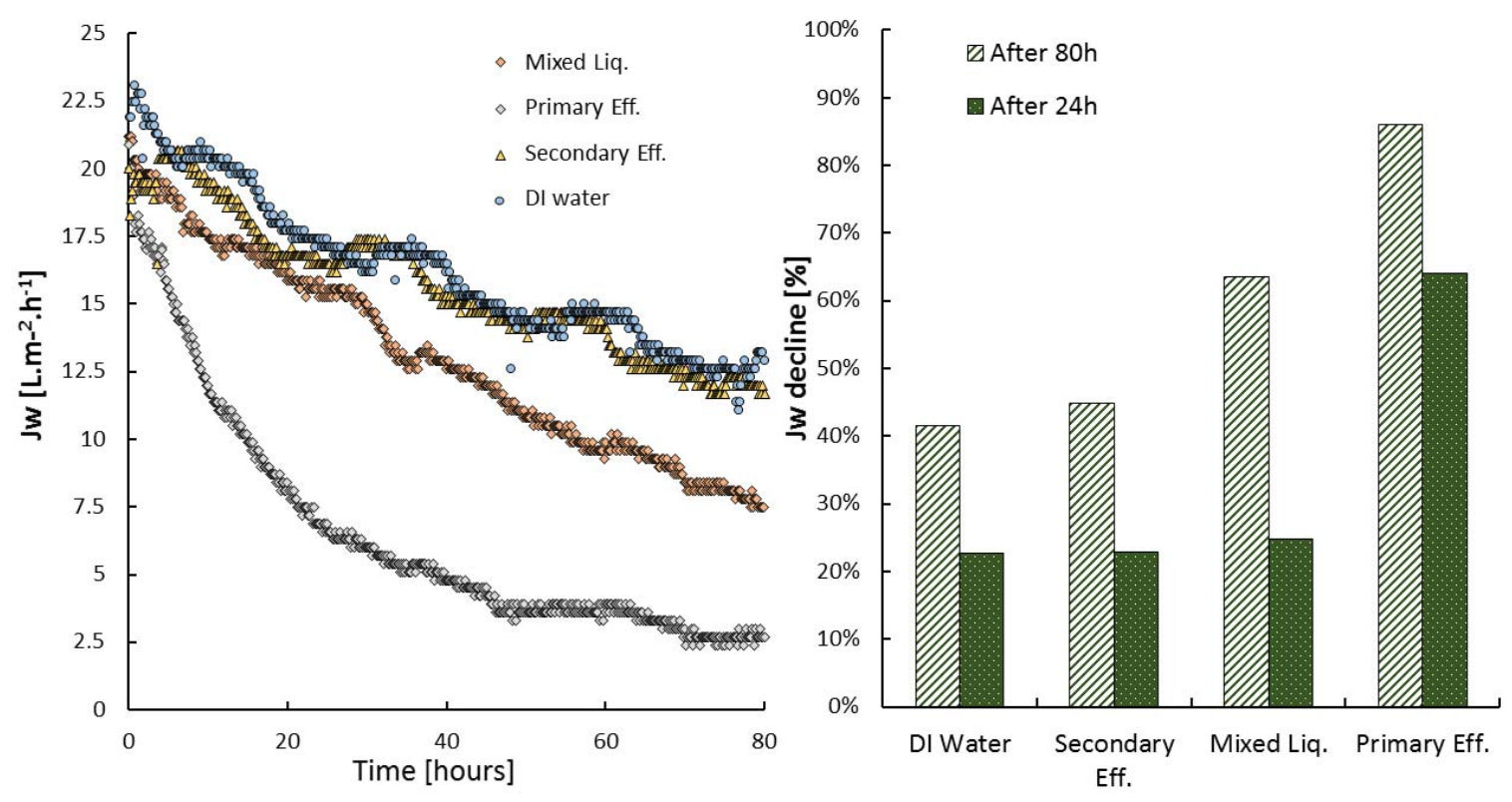

330 Figure 4. Water flux as a function of water recovery for four different feed solutions (left). Water flux decline 331 percentages are provided after $24 \mathrm{~h}$ and $80 \mathrm{~h}$ of operation (right). Operating parameters: Draw solution = real seawater; 332 Feed solutions = DI, Secondary Eff., Mixed Liq. And Primary Eff.; Operating time = 80 hours.

$333 \quad$ 3.3.3 Analysis of the fouling layer

334 EDX and FTIR analyses were carried out to investigate the composition of the fouling layers. The results are gathered in both Figure 5 and Figure 6.

336 The EDX analysis revealed that several elements are present in the fouling layer and that the 337 composition of the fouling layer seems to be roughly the same independently of the feed solution. The 338 presence of calcium and magnesium were not a surprise, as these divalent ions act as fouling promoters 339 by forming complexes with organic molecules and biological matter. This phenomenon is known for 340 filtration and RO processes but was also highlighted in the osmotic dilution of seawater [11, 26, 27].

341 Phosphorous and sulphur peaks indicate that sulphate and phosphate ions are probably acting as fouling 342 promoters, especially when primary effluent WW is used. It can also be linked to the amount of 343 biological matter, as proteins are abundant in $\mathrm{P}$ and $\mathrm{S}$. The $\mathrm{C}$ and $\mathrm{O}$ peaks correspond to the active layer, 344 visible below the fouling layer. Finally, crystals on top of the fouling layer could be seen with the SEM 345 images (Figure S3). However, they are sparse and do not cover most of the membrane surface. Instead, 346 a uniform layer of organic fouling could be noticed from the pictures. When primary effluent was used, 347 this layers than formed several crakes when it dried out. 

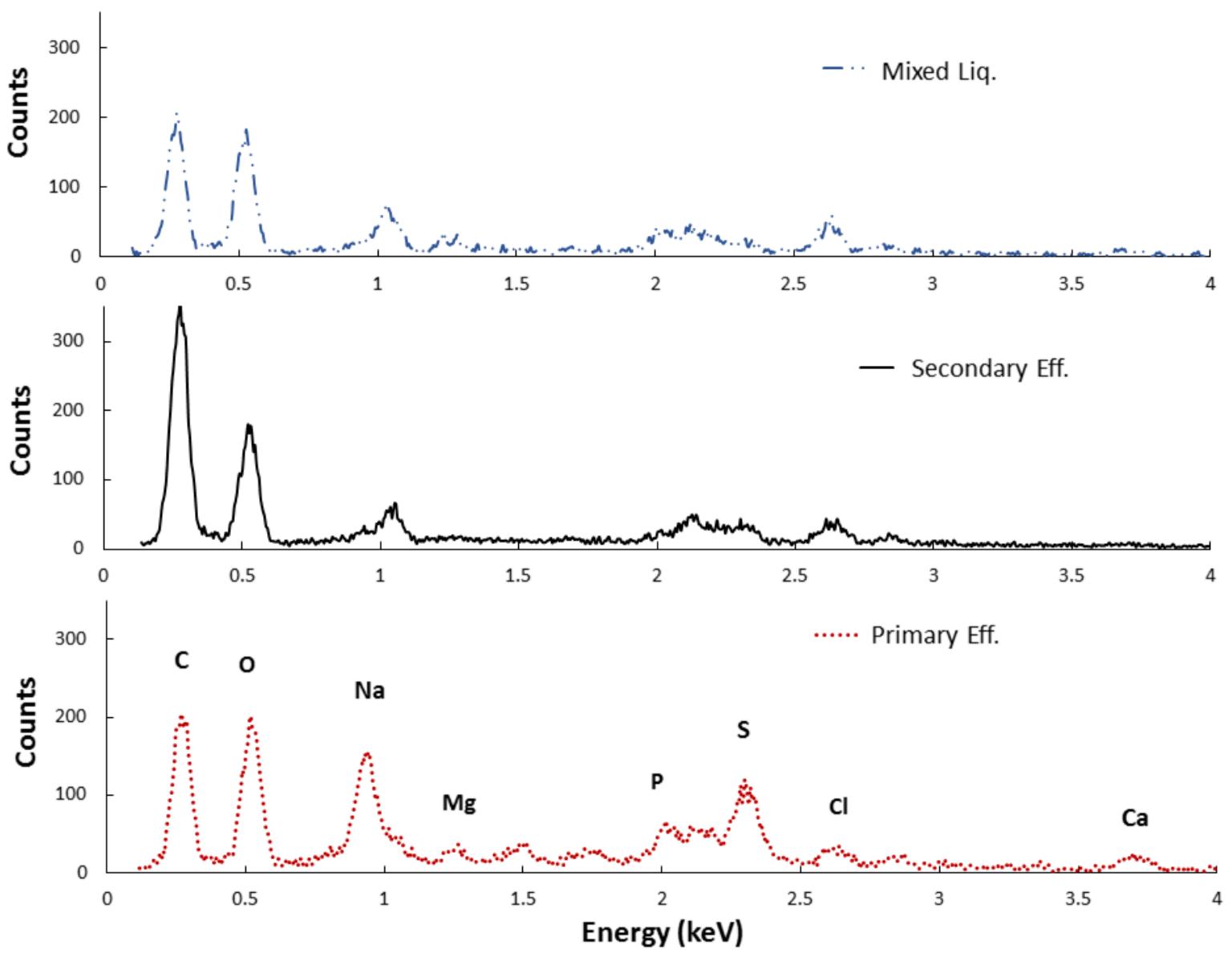

Figure 5. EDX analysis of the surface of the fouling layer on the membranes.

350 The FTIR analysis confirms the regularity of the composition of the fouling layer, as the same peaks 351 appeared for the three fouled membranes. These peaks were not visible in the pristine membrane. The 352 associated wavenumber has typically been associated to organic matter and could correspond to the 353 following bonds, usually found in organic foulants: $\mathrm{O}-\mathrm{H}\left(3300 \mathrm{~cm}^{-1}\right), \mathrm{C}=\mathrm{C}\left(1630 \mathrm{~cm}^{-1}\right), \mathrm{COO}^{-}(1550$ $\left.354 \mathrm{~cm}^{-1}\right), \mathrm{C}-\mathrm{O}\left(1080 \mathrm{~cm}^{-1}\right)[28]$. 


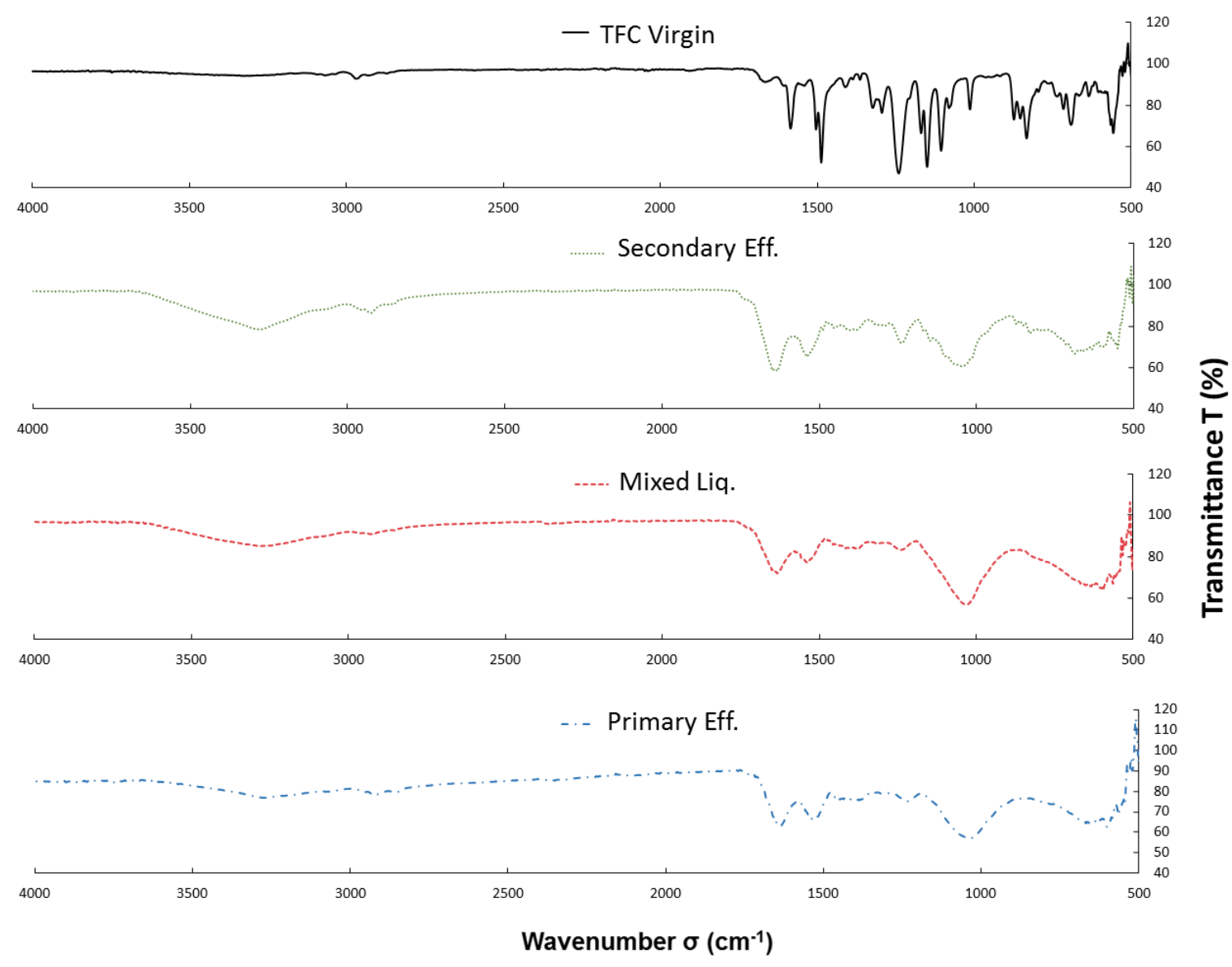

Figure 6. FTIR of fouled membranes compared to a virgin TFC membrane (in black).

357 To sum up, as expected from the FO tests, the raw WW caused a more noticeable fouling cake on top 358 of the membrane active layer. The presence of known fouling precursors, e.g. $\mathrm{Mg}^{2+}, \mathrm{PO}_{4}{ }^{3-}, \mathrm{Ca}^{2+}$ and 359 organic matter, confirmed that both organic and inorganic fouling happened. On the contrary, when 360 secondary effluent was used, the analysis of membrane coupon did not show significant evidences of 361 organic and inorganic precipitates.

\section{$362 \quad 3.4 \quad$ Evaluation of the produced water quality}

363 To assess the possible nutrients contamination of the diluted seawater, nitrogen, phosphorous and TOC

364 were measured in the DS. It should be noted that, in this concept, the diluted seawater is supposed to 365 pass through a second barrier, i.e. RO. The RO filtration step would further reduce the N, P and TOC 366 concentrations in the final effluent. These results refer to the tests conducted with synthetic seawater as 367 DS and primary effluent WW as FS. Synthetic seawater was used instead of real in order not to bias the results since the real seawater itself has nitrogen compounds.

369 In this study, attention was focused on the rejection of $\mathrm{NH}_{4}{ }^{+}$since, among all the nutrients, it is known 370 to be among the hardest to be rejected [29]. Other studies have already demonstrated that the rejection 371 of phosphate and COD is almost $100 \%$ [29]. The poor rejection of ammonia is to be attributed to its 
small hydrated radii (i.e. $3.31 \AA$ ) and positive charge (being the polyamide layer negatively charged).

373 Figure 7 shows how the rejection decreased when primary effluent WW was used as FS. This can be explained by the fact that the concentration of contaminants is higher in raw wastewater than in secondary effluent.

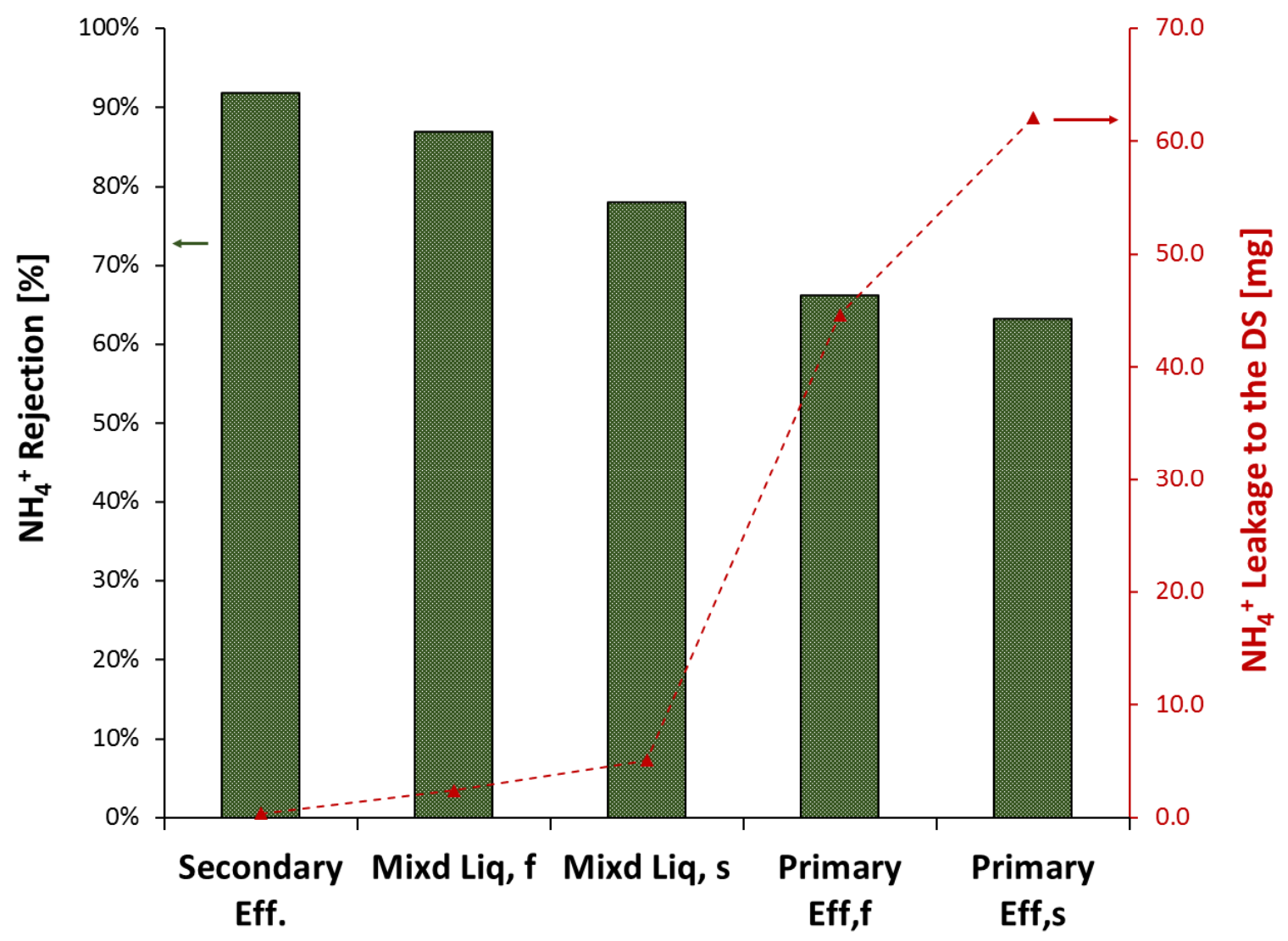

Figure 7. Rejection of $\mathrm{NH}_{4}{ }^{+}$after $8 \mathrm{~h}$ experiments having synthetic seawater as DS and different real wastewaters as FS (columns). The dotted line with the markers indicates the amount of $\mathrm{NH}_{4}{ }^{+}$that leaked through the $\mathrm{FO}$ membrane to the DS after the filtration.

To conclude, raw WW showed high $\mathrm{NH}_{4}{ }^{+}$leakage in the diluted DS, while both secondary effluent and mixed liquor showed final $\mathrm{NH}_{4}{ }^{+}$concentrations less than $2 \mathrm{mg} / \mathrm{L}$.

\subsection{Modelling the system performances}

384 Modelling the water fluxes with different FS was performed using Equation (3) to assess how the measured data diverge from the theoretical trend. The divergence from measured data to modelled one was used as a further indication of membrane fouling. In fact, this model does not take into account the flux decline due to membrane fouling. The model was firstly validated with DI water as FS before proceeding with WW (Figure 8). It can be seen that the predictions fit quite well the measured data. In Figure 8 , the experimental water fluxes using real seawater and wastewaters results are plotted together 
with the fluxes predicted with the model.

391 By looking at the second graph from the top in Figure 8, it can be seen that the model predicted quite accurately the FO water flux when secondary effluent is used as FS. Only at the very end of the filtration,

393 the measured flux is slightly lower than the modelled. This is probably because in the low end of the

394 experiment the secondary effluent solution has been concentrated enough to created moderated fouling 395 on the membrane.

396 Fouling on the low-end of the filtration is even more noticeable when mixed liquor is used as FS. In 397 this case a clear divergence from the model happens after about 30 hours. Finally, when primary effluent 398 is used, soon after the beginning of the experiment the model over-predicted the measured data due to 399 the severe flux decline.
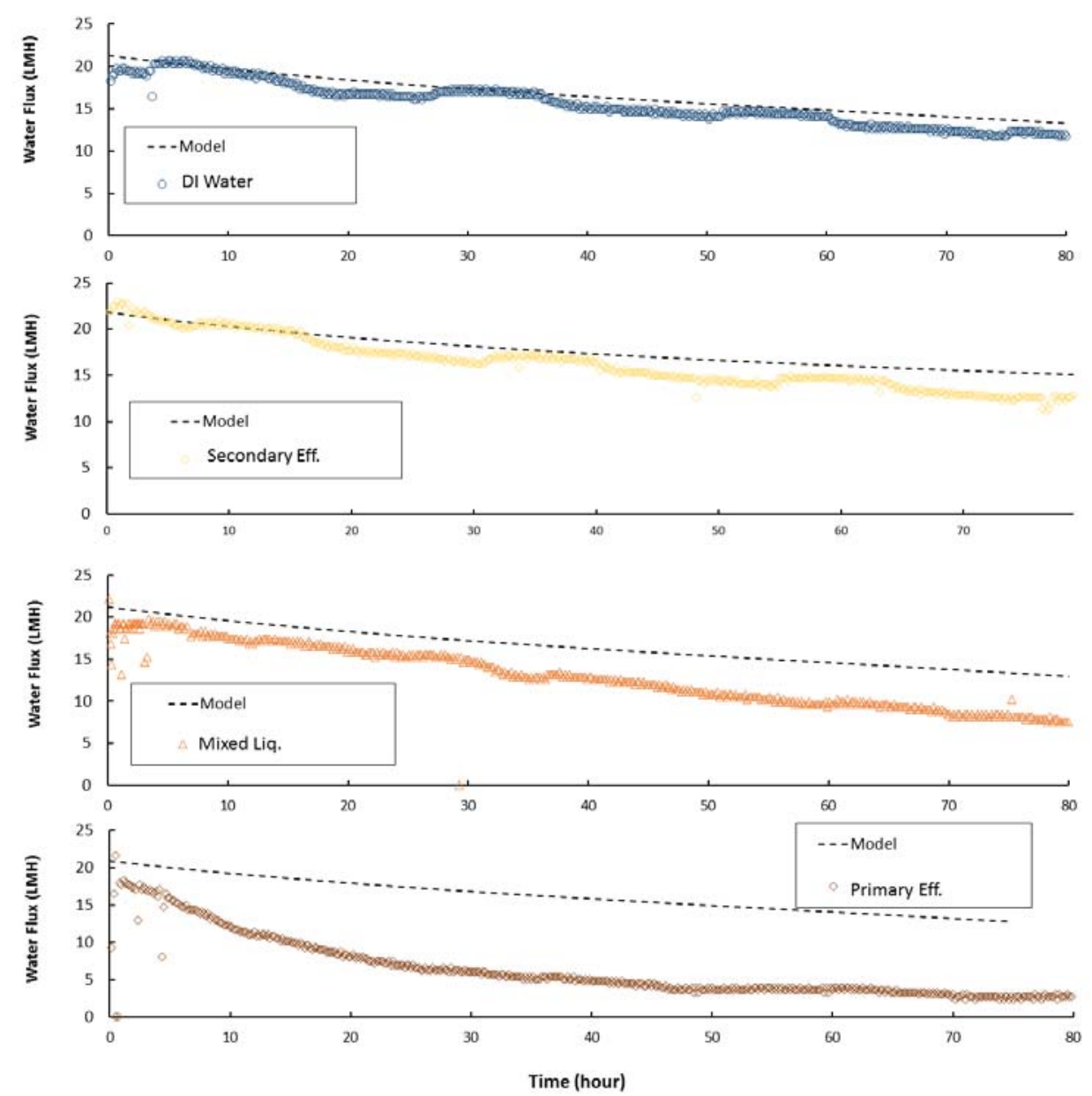
401 Figure 8. Predicted and measured water fluxes. The model used to predict the water flux trend was developed from
402 Equation 3 using the membrane parameters outlined in Table 4. Excluding the top graph, all the experiments were 403 conducted with real seawater as DS and real wastewaters as FS.

404 To sum up, a water flux model was developed and validated with standard experiments using DI water 405 as FS and seawater as DS. After validation, the model was applied on real wastewaters to see its 406 deviation from the measured data. As expected, primary effluent displayed the most visible deviation 
407 even after few hours. When mixed liquor was used, the divergence between model and experiment 408 occurred after about 30 hours, while secondary effluent showed little to no discrepancies with the 409 modelled data.

\section{Conclusions}

411 Newly developed and commercially available TFC membranes were used to evaluate their 412 performances and fouling tendency in the FO-RO hybrid process for wastewater reclamation and 413 seawater dilution. Real wastewater and real seawater are used as feed and draw solution to get 414 meaningful results. Real seawater achieved an initial water flux of about $22.5 \mathrm{Lm}^{-2} \mathrm{~h}^{-1}$ when biologically 415 treated secondary effluent was used. It was also found that the secondary effluents caused negligible 416 flux decline. Also, the ammonia rejection was measured to be $>80 \%$.

417 On the contrary, when raw wastewater was used severe fouling and flux decline was observed. Pre418 treatment with sedimentation or coagulation-flocculation was not enough to ensure a good FO 419 performance during the filtration. A possible explanation is the presence of high concentrations of low 420 molecular weight organic compounds, measured with LC-OCD. These compounds are suspected to act 421 as fouling promotors thereby significantly decreasing the filtration time of the experiment. The analysis 422 of the fouling layers shows that the composition did not change significantly when using secondary 423 effluent or mixed liquor. However, when raw WW was used, a higher amount of divalent ions (e.g. $\left.424 \mathrm{Ca}^{2+}, \mathrm{Mg}^{2+}\right)$ and $\mathrm{PO}_{4}{ }^{3-}$ were found with the EDX. Modelling the water flux of the process helped validate 425 the above conclusions.

426 To conclude, if mixed liquor or secondary effluent is chosen as feed solution, commercially available 427 FO membranes were able to produce a good quality permeate, without severe fouling, even during long428 term filtration ( $>80$ hours). Given a stable FO performance, the high quality of diluted seawater will 429 likely decrease the cost of the downstream RO filtration for potable water production. 


\section{Acknowledgements}

433 This project is supported by the Australian Research Council (ARC) through the ARC Research Hub 434 for Energy-efficient Separation (IH170100009) and by Industrial Facilities \& Infrastructure Research 435 Program (code 18IFIP-B088091-05) by Ministry of Land, Infrastructure and Transport of Korean 436 Government.

437 
439 [1] UN General Assembly, Resolution 70/1, Transforming Our World: The 2030 Agenda For 440 Sustainable Development, A/RES/70/1 in, undocs.org/A/RES/70/1, 2015.

441 [2] M.A. Montgomery, M. Elimelech, Water and sanitation in developing countries: including health in 442 the equation, Environ Sci Technol, 41 (2007) 17-24.

443 [3] N.W. Arnell, D.P. van Vuuren, M. Isaac, The implications of climate policy for the impacts of climate change on global water resources, Global Environmental Change, 21 (2011) 592-603.

[4] B.E. Jiménez Cisneros, T. Oki, N.W. Arnell, G. Benito, J.G. Cogley, P. Döll, T. Jiang, and S.S. Mwakalila, Freshwater Resources, in: C.B. Field, V.R. Barros, D.J. Dokken, K.J. Mach, M.D. Mastrandrea, T.E. Bilir, M. Chatterjee, K.L. Ebi, Y.O. Estrada, R.C. Genova, B. Girma, E.S. Kissel, A.N. Levy, S. MacCracken, P.R. Mastrandrea, and L.L. White (eds.) (Ed.) Climate Change 2014: Impacts, Adaptation, and Vulnerability. Part A: Global and Sectoral Aspects. Contribution of Working Group II to the Fifth Assessment Report of the Intergovernmental Panel on Climate Change Cambridge University Press, Cambridge, United Kingdom and New York, NY, USA, 2014, pp. 229-269.

[5] M.A. Shannon, P.W. Bohn, M. Elimelech, J.G. Georgiadis, B.J. Marinas, A.M. Mayes, Science and technology for water purification in the coming decades, Nature, 452 (2008) 301-310.

[6] National Research Council, Desalination: A National Perspective, The National Academies Press, Washington, DC, 2008.

[7] R. Valladares Linares, Z. Li, V. Yangali-Quintanilla, N. Ghaffour, G. Amy, T. Leiknes, J.S. Vrouwenvelder, Life cycle cost of a hybrid forward osmosis - low pressure reverse osmosis system for seawater desalination and wastewater recovery, Water Research, 88 (2016) 225-234.

[8] M. Elimelech, W.A. Phillip, The Future of Seawater Desalination: Energy, Technology, and the Environment, Science, 333 (2011) 712-717.

[9] Q. Li, Z. Xu, I. Pinnau, Fouling of reverse osmosis membranes by biopolymers in wastewater secondary effluent: Role of membrane surface properties and initial permeate flux, Journal of Membrane Science, 290 (2007) 173-181.

[10] T. Asano, A.D. Levine, Wastewater reclamation, recycling and reuse: past, present, and future, Water Science and Technology, 33 (1996) 1-14.

[11] V. Parida, H.Y. Ng, Forward osmosis organic fouling: Effects of organic loading, calcium and membrane orientation, Desalination, 312 (2013) 88-98.

[12] L. Chekli, S. Phuntsho, J.E. Kim, J. Kim, J.Y. Choi, J.-S. Choi, S. Kim, J.H. Kim, S. Hong, J. Sohn, H.K. Shon, A comprehensive review of hybrid forward osmosis systems: Performance, applications and future prospects, Journal of Membrane Science, 497 (2016) 430-449.

[13] N.T. Hancock, P. Xu, M.J. Roby, J.D. Gomez, T.Y. Cath, Towards direct potable reuse with forward osmosis: Technical assessment of long-term process performance at the pilot scale, Journal of Membrane Science, 445 (2013) 34-46.

[14] T.Y. Cath, N.T. Hancock, C.D. Lundin, C. Hoppe-Jones, J.E. Drewes, A multi-barrier osmotic dilution process for simultaneous desalination and purification of impaired water, Journal of Membrane Science, 362 (2010) 417-426.

[15] V. Yangali-Quintanilla, Z. Li, R. Valladares, Q. Li, G. Amy, Indirect desalination of Red Sea water with forward osmosis and low pressure reverse osmosis for water reuse, Desalination, 280 (2011) 160166.

[16] C. Boo, M. Elimelech, S. Hong, Fouling control in a forward osmosis process integrating seawater desalination and wastewater reclamation, J. Membr. Sci., 444 (2013) 148-156.

[17] Q. She, R. Wang, A.G. Fane, C.Y. Tang, Membrane fouling in osmotically driven membrane processes: A review, Journal of Membrane Science, 499 (2016) 201-233.

[18] A. Tiraferri, N.Y. Yip, A.P. Straub, S. Romero-Vargas Castrillon, M. Elimelech, A method for the simultaneous determination of transport and structural parameters of forward osmosis membranes, Journal of Membrane Science, 444 (2013) 523-538.

[19] C.Y. Tang, Q. She, W.C.L. Lay, R. Wang, A.G. Fane, Coupled effects of internal concentration polarization and fouling on flux behavior of forward osmosis membranes during humic acid filtration, Journal of Membrane Science, 354 (2010) 123-133.

[20] J. Zhang, Q. She, V.W.C. Chang, C.Y. Tang, R.D. Webster, Mining nutrients (N, K, P) from urban 
491 source-separated urine by forward osmosis dewatering, Environmental Science and Technology, 48 492 (2014) 3386-3394.

493 [21] S.A. Huber, A. Balz, M. Abert, W. Pronk, Characterisation of aquatic humic and non-humic matter 494 with size-exclusion chromatography - organic carbon detection - organic nitrogen detection (LC-OCD495 OND), Water Research, 45 (2011) 879-885.

496 [22] J. Ren, J.R. McCutcheon, A new commercial thin film composite membrane for forward osmosis, 497 Desalination, 343 (2014) 187-193.

498 [23] Z. Wang, J. Tang, C. Zhu, Y. Dong, Q. Wang, Z. Wu, Chemical cleaning protocols for thin film 499 composite (TFC) polyamide forward osmosis membranes used for municipal wastewater treatment, 500 Journal of Membrane Science, 475 (2015) 184-192.

501 [24] J. Wei, C. Qiu, C.Y. Tang, R. Wang, A.G. Fane, Synthesis and characterization of flat-sheet thin 502 film composite forward osmosis membranes, Journal of Membrane Science, 372 (2011) 292-302.

503 [25] F. Lotfi, L. Chekli, S. Phuntsho, S. Hong, J.Y. Choi, H.K. Shon, Understanding the possible 504 underlying mechanisms for low fouling tendency of the forward osmosis and pressure assisted osmosis 505 processes, Desalination, (2017).

506 [26] S. Lee, C. Boo, M. Elimelech, S. Hong, Comparison of fouling behavior in forward osmosis (FO) 507 and reverse osmosis (RO), J. Membr. Sci., 365 (2010) 34-39.

508 [27] B. Mi, M. Elimelech, Organic fouling of forward osmosis membranes: fouling reversibility and 509 cleaning without chemical reagents, J. Membr. Sci., 348 (2010) 337-345.

510 [28] C.S. Uyguner, M. Bekbolet, J. Swietlik, Natural organic matter: Definitions and characterization, 511 Control of disinfection by-products in drinking water systems, (2007) 253-277.

512 [29] R. Valladares Linares, Z. Li, M. Abu-Ghdaib, C.-H. Wei, G. Amy, J.S. Vrouwenvelder, Water 513 harvesting from municipal wastewater via osmotic gradient: An evaluation of process performance, 514 Journal of Membrane Science, 447 (2013) 50-56. 